\title{
Prevalence, knowledge and attitudes of menopausal symptoms among women aged 40-60 years and their associated factors in a semi urban area, Matara district, Sri Lanka
}

\author{
Samudra T. Perera ${ }^{1}$, Sampatha E. Goonewardena ${ }^{2 *}$
}

\author{
${ }^{1}$ Department of Nursing and Midwifery, Faculty of Allied Health Sciences, University of Sri Jayewardenepura, Sri \\ Lanka \\ ${ }^{2}$ Department of Community Medicine, Faculty of Medical Sciences, University of Sri Jayewardenepura, Sri Lanka
}

Received: 20 April 2020

Accepted: 29 May 2020

\section{*Correspondence: \\ Dr. Sampatha E. Goonewardena, \\ E-mail: sampatha@sjp.ac.lk}

Copyright: (C) the author(s), publisher and licensee Medip Academy. This is an open-access article distributed under the terms of the Creative Commons Attribution Non-Commercial License, which permits unrestricted non-commercial use, distribution, and reproduction in any medium, provided the original work is properly cited.

\begin{abstract}
Background: Menopause is naturally created milestone in a women's life. Every woman experiences unique menopausal symptoms that may be physiological, psychological or both. The aim of this study was to determine the prevalence, knowledge and attitudes of menopausal symptoms among women aged 40-60 years and their associated factors in a semi urban area, Matara district, Sri Lanka.

Methods: A descriptive cross-sectional community-based study was carried out among 212 women ages 40-60 years in three selected Grama Niladhari divisions Matara district, Sri Lanka. Data was collected using an interviewer administered questionnaire. A validated menopausal rating scale used to measure menopausal symptoms. Data was analysed using SPSS version 23 . A probability of $\mathrm{p}<0.05$ was considered significant.

Results: The mean age of menopause of the study population was 47.84 years $(\mathrm{SD}=4.048)$. The most prevalent somatic symptoms were hot flushes 157 (74.1\%), joint and muscular discomfort 138 (65.1\%), sleeping problems 126 $(59.5 \%)$ and heart discomfort $112(52.9 \%)$. Majority (>50\%) reported having psychological symptoms and minority reported urogenital symptoms. All menopausal symptoms were more prevalent and was statistically significant in post-menopausal stage for urogenital symptoms. According to the knowledge categorization, majority $(>50 \%)$ of the respondents had good knowledge regarding menopause. Mean knowledge score was 68.4 \pm 18 . Married women and more educated women had better knowledge regarding menopause $(\mathrm{p}<0.05)$. Public health midwives were the main source of knowledge.

Conclusions: Education, creating awareness and providing suitable interventions can be done to improve the quality of life of women through menopausal transitional period.
\end{abstract}

Keywords: Attitudes, Knowledge, Menopause, Menopausal symptoms, Prevalence

\section{INTRODUCTION}

Menopause is the time in women's life when menstrual periods permanently stop. World Health Organization defines as the time there has been no menstrual periods for 12 consecutive months and no other biological and physiological cause can be identified. Every woman faces this transitional period in their middle age of life.
Majority of the women experience various physiological and psychological changes during this period. According to Shakila's report there are 3 phases of menopause. The time upto the last menstrual period called premenopausal phase. The time period around the menopause, series of menstrual irregularities and endocrine changes are occurring in peri- menopausal/ menopausal transition phase. Post-menopausal phase 
recognized after 12 months of amenorrhea. ${ }^{1}$ The exact age of menopause varies from population to population in the worldwide. $^{2}$ Generally, with advancing age of 50 years, range between 40-60 years. ${ }^{3}$ When advancing age, the prevalence of menopausal symptoms becomes mild to severe status gradually due to hormone deficiency. Due to deficiency of female sex hormones, specially oestrogen some symptoms mainly can occur in every woman such as bone problems, vaginal dryness, insomnia, hot flushes, and emotional problems. Hot flushes and night sweats are the most common symptoms (approximately 70\%) reported in Europe and North African women. ${ }^{4}$ Psychological symptoms associated with menopause are fatigue, irritability and anxiety. One of the important challenges is to understand the mood disorders related to menopause. ${ }^{4}$ Mood disorders are one of the main comorbid condition of sexual dysfunction in postmenopausal stage. Not only that, but weight gain also affected for poor sexual functioning. Most of the women noted negative social aspects of aging and also noted that they were treated negatively within the society. ${ }^{5}$ This also affects for the behavioural changes of the women within the society. According to Nuzrat's report there are various associated factors that affect the menopausal status of the women. It has been shown the factors such as socioeconomic background, education level of the women were mainly affected for the knowledge about menopause. ${ }^{6}$ According to the previous findings from the worldwide, the distribution of menopausal symptoms varied in different ethnics and racial backgrounds. ${ }^{7}$ In Sri Lanka, there were researches done recently in Northern Province, Western province and Southern province to describe the symptoms in menopause..$^{1,8-9}$

Several studies from various countries, women reported that they had menopausal symptoms in all pre, peri and post-menopausal phases. But the severity of the symptoms was different according to the menopausal phase. ${ }^{10}$ Nearly $25 \%$ of Sri Lankan population has been identified as women between the age group of 35-60 years. ${ }^{11}$ That means one fourth of population has a risk of menopause and its symptoms. Hence the women age between 40-60 years are more prone to having menopausal symptoms. There are very few limited studies on the menopause in Sri Lankan women compared to western countries. ${ }^{8}$

The above-mentioned study also identifies the lack of knowledge about the prevalence of menopausal symptoms of women in Sri Lanka. So, it's important to research about this topic to determine the prevalence of menopausal symptoms among women for the future health care requirements. When they had menopausal symptoms most of the women took medications for temporary relief. Further, women should be informed on available therapies and management strategies regarding menopausal symptoms. The aim of the study is to describe the prevalence of menopausal symptoms, knowledge and attitudes of Sri Lankan women and to assess the awareness of hormone therapy for the menopausal symptoms after menopause among women in selected semi urban area, Matara district, Sri Lanka.

\section{METHODS}

A community based cross sectional descriptive study was carried out in the Southern province of Sri Lanka in one Divisional Secretariat area (DS). The districts of Sri Lanka are divided into administrative sub units known as divisional secretariats. Women aged between 40-60 years were selected and women who had undergone hysterectomy and bilateral oophorectomy, taking hormone replacement therapy and on chemotherapy for any malignancy were excluded. At $95 \%$ significance level, assuming $74.7 \%$ commonly prevalent menopausal symptoms according to Waidyasekera's report and assuming a 5\% nonresponse rate, the final sample size was 212. All the roads in selected division were listed and every second house was randomly selected. Any women between the ages 40-60 years who fulfil the inclusion criteria were selected until the final sample size was achieved. A pre tested, interviewer administered questionnaire was developed which consisted of sociodemographic data, regarding gynecology and medical history, regarding prevalence of menopausal symptoms using menopausal rating scale (MRS), knowledge and attitudes regarding menopause after obtaining informed written consent. MRS is a health-related quality of life scale which has been well accepted internationally translated to several languages. ${ }^{12}$ The women were questioned to report their symptoms and to rate the severity as mild, moderate, severe and very severe. The scale has 11 symptoms and the score was generated by adding the score for each given symptom. Scoring for each symptom was given as follows: none $=0$, mild $=1$, moderate $=2$, severe $=3$, very severe $=4$.

SPSS (statistical package for social sciences) version 23 was used to enter data and for analysis. Descriptive statistics was used for summarizing and presenting data. The association between knowledge and associated factors was analysed using the Chi square test and $\mathrm{P}<$ 0.05 were taken as a significant level. To calculate the knowledge each correct statement was given " 1 " mark and " 0 " mark for incorrect and don't know responses. There were 10 knowledge questions and the maximum score was 10 marks. The mean overall score of the marks was $68.4 \pm 18$. Then depending on the mean value, overall knowledge divided in to two groups named good and poor knowledge. Attitudes regarding menopause were analysed by using Likert scale. Ethical approval was obtained from Ethics Review Committee, Faculty of Medical Sciences, University of Sri Jayewardenepura, Sri Lanka.

\section{RESULTS}

The mean age of menopause of the study population was 47.84 years $(\mathrm{SD}=4.048)$. Majority $(\mathrm{N}=207,97.6 \%)$ of the study population were Sinhala, Buddhist and were 
married. More than $75 \%$ were living with their children. Most of the participants had studied above O/L. ( $N=129$, $60.8 \%)$. Almost, half of the participants were in the postmenopausal category $(\mathrm{N}=107)(50.5 \%)$ (Table 1$)$.

Table 1: Frequency distribution of socio-demographic characteristics of study population $(\mathrm{N}=\mathbf{2 1 2})$.

\begin{tabular}{|lll|}
\hline Characteristics & Frequency (N) & Percentage \\
\hline Age (years) & & \\
\hline$<50$ & 113 & $53.3 \%$ \\
\hline$>50$ & 99 & $46.7 \%$ \\
\hline Ethnicity & & \\
\hline Sinhala & 207 & $97.6 \%$ \\
\hline Tamil & 1 & $0.5 \%$ \\
\hline Muslim & 4 & $1.9 \%$ \\
\hline Religion & & \\
\hline Buddhist & 201 & $94.8 \%$ \\
\hline Christian & 6 & $2.8 \%$ \\
\hline Islam & 4 & $1.9 \%$ \\
\hline Hindu & 1 & $0.5 \%$ \\
\hline Marital status & & \\
\hline Married & 175 & $82.5 \%$ \\
\hline Single & 21 & $9.9 \%$ \\
\hline others & 16 & $7.5 \%$ \\
\hline Education level & & \\
\hline Up to o/l & 83 & $39.2 \%$ \\
\hline Above o/l & 129 & $60.8 \%$ \\
\hline Living status & & $17 \%$ \\
\hline With partner & 36 & $75 \%$ \\
\hline With children/others & 159 & $8 \%$ \\
\hline Alone & 17 & \\
\hline & & \\
\hline
\end{tabular}

Table 2: Frequency distribution of prevalence of menopausal symptoms among study population $(\mathrm{N}=212)$.

\begin{tabular}{|lllll|}
\hline $\begin{array}{l}\text { Menopausal } \\
\text { symptoms }\end{array}$ & $\begin{array}{l}\text { Mild- } \\
\text { moderate }\end{array}$ & $\begin{array}{l}\text { Severe-very } \\
\text { severe }\end{array}$ \\
\cline { 2 - 5 } & No. & $\%$ & No. & $\%$ \\
\hline Somatic & & & & \\
\hline Hot flushes, sweating & 124 & $58.5 \%$ & 33 & $15.6 \%$ \\
\hline Heart discomfort & 98 & $46.3 \%$ & 14 & $6.6 \%$ \\
\hline $\begin{array}{l}\text { Joint and muscular } \\
\text { discomfort }\end{array}$ & 94 & $44.3 \%$ & 44 & $20.8 \%$ \\
\hline $\begin{array}{l}\text { Sleep problems } \\
\text { Psychological }\end{array}$ & 89 & $42 \%$ & 37 & $17.5 \%$ \\
\hline Depressive mood & 100 & $47.2 \%$ & 20 & $9.4 \%$ \\
\hline Irritability & 88 & $41.5 \%$ & 19 & $9 \%$ \\
\hline Anxiety & 91 & $43 \%$ & 25 & $11.7 \%$ \\
\hline $\begin{array}{l}\text { Physical and mental } \\
\text { exhaustion }\end{array}$ & 93 & $43.9 \%$ & 43 & $20.3 \%$ \\
\hline Urogenital & & & & \\
\hline Sexual problems & 69 & $32.6 \%$ & 1 & $0.5 \%$ \\
\hline Bladder problems & 85 & $40.1 \%$ & 20 & $9.4 \%$ \\
\hline Dryness of vagina & 87 & $40.1 \%$ & 8 & $3.8 \%$ \\
\hline
\end{tabular}

Table 2 illustrates the prevalence of menopausal symptoms as assessed by the modified MRS according to the most frequent complaints. The most prevalent somatic symptoms were hot flushes $157(74.1 \%)$, joint and muscular discomfort $138(65.1 \%)$, sleeping problems 126 $(59.5 \%)$ and heart discomfort 112 (52.9\%). Among psychological symptoms majority had physical and mental exhaustion $136(64.2 \%)$, depressive mood 120 $(56.6 \%)$, anxiety $116(54.7 \%)$ and irritability 107 $(50.5 \%)$. When inquired about urogenital symptoms, most stated bladder problems 105 (49.5\%), dryness of vagina $95(43.9 \%)$ and $70(33.1 \%)$ women reported sexual problems. However, only 28 (13.2\%) had medications for above symptoms (Table 2).

Symptom prevalence in pre-, peri- and post- menopausal women is shown in Table 3. Among all menopausal symptoms were more prevalent in post-menopausal compared with pre- and peri-menopausal stages. Postmenopausal women had a higher proportion of menopausal symptoms when compared to pre/ menopausal transition states such as presence of hot flushes $(p=0.02)$, heart discomfort $(p=0.01)$, sleep problems $(p=0.02)$, depressive moods $(p=0.045)$, irritability $(\mathrm{p}=0.000)$, anxiety $(\mathrm{p}=0.019)$, physical and mental exhaustion $(\mathrm{p}=0.000)$ and joint and muscular discomfort $(\mathrm{p}=0.000)$. These differences were statistically significant $(p<0.05)$. However, the symptoms of sexual problems, bladder problems and dryness of vagina was reported by similar numbers by all three categories $(\mathrm{p}>0.05)$ (Table 3$)$.

According to the knowledge categorization, majority $(>50 \%)$ of the respondents had good knowledge regarding menopause. The mean knowledge score was $68.4 \pm 18$. Majority $157(74.1 \%)$ of women were aware about the meaning of menopause and how it occurs. However, most 142 (67\%) of them had no knowledge that the occurrence of symptoms was due to the hormonal change during menopause. Majority 198 (93.4\%) knew the age range of when menopause occurs. Most, 147 $(69.3 \%)$ women consider menopause as natural process of aging and $38(17.9 \%)$ perceived it as a disease. Most $178(84 \%)$ women knew that they no longer become pregnant after menopause and 177 (83.5\%) had knowledge about early indicator of menopause as menstrual irregularities. Nearly $88(41.5 \%)$ women were not aware about hormone replacement therapy and a majority $115(54.2 \%)$ of women had no idea about the future risk factors of menopause such as cardiovascular problems, osteoporosis (Table 4).

Table 5 shows that the frequency distribution of women's attitudes towards menopause and its symptoms. Almost half $(48 \%)$ agreed to see a doctor at the menopause. Few $(37.3 \%)$ women considered that the menopause is the best thing that ever happened. Almost half of women (50\%) were happy about that they can quit worrying about getting pregnant. Majority $87(41 \%)$ of women thought that they felt better after menopause. Few women 
stated $77(36.3 \%)$ that they were unhappy about the loss of youth and beginning of the end of life. Majority 104 $(51.5 \%)$ were agreed about natural approaches for treating menopausal symptoms are better than hormone replacement therapy (Table 5).

Table 3: Prevalence of menopausal symptoms compared among menopausal stages.

\begin{tabular}{|llllllll|} 
& \multicolumn{2}{l}{ Pre- menopausal } & \multicolumn{2}{l|}{ Menopausal transition } & \multicolumn{2}{l|}{ Post- menopausal } & p value \\
\hline Menopausal symptoms & No. & $\mathbf{\%}$ & No. & \% & No. & \% & \\
\hline Hot flushes, sweating & 39 & $24.8 \%$ & 34 & $21.7 \%$ & 84 & $53.5 \%$ & 0.02 \\
\hline Heart discomfort & 25 & $22.2 \%$ & 30 & $26.8 \%$ & 57 & $50.9 \%$ & 0.01 \\
\hline Sleep problems & 30 & $23.8 \%$ & 26 & $20.6 \%$ & 70 & $55.6 \%$ & 0.02 \\
\hline Joint and muscular discomfort & 29 & $21 \%$ & 29 & $21 \%$ & 80 & $58 \%$ & 0.000 \\
\hline Depressive mood & 34 & $28.3 \%$ & 29 & $24.2 \%$ & 57 & $47.5 \%$ & 0.045 \\
\hline Irritability & 25 & $23.4 \%$ & 30 & $28 \%$ & 52 & $48.6 \%$ & 0.000 \\
\hline Anxiety & 31 & $26.7 \%$ & 29 & $25 \%$ & 56 & $48.3 \%$ & 0.019 \\
\hline Physical and mental exhaustion & 31 & $22.8 \%$ & 22 & $16.2 \%$ & 83 & $61 \%$ & 0.000 \\
\hline Sexual problems & 18 & $25.7 \%$ & 19 & $27.1 \%$ & 33 & $47.1 \%$ & 0.062 \\
\hline Bladder problems & 25 & $23.8 \%$ & 22 & $21 \%$ & 58 & $55.2 \%$ & 0.072 \\
\hline Dryness of vagina & 26 & $27.4 \%$ & 24 & $25.3 \%$ & 45 & $47.4 \%$ & 0.063 \\
\hline
\end{tabular}

Table 4: Frequency distribution of knowledge regarding menopause and its symptoms among study population.

\begin{tabular}{|lllll|}
\hline Characteristics & \multicolumn{2}{l}{ Good knowledge } & \multicolumn{2}{l|}{ Poor knowledge } \\
\cline { 2 - 6 } & No. & \% & No. & \% \\
\hline Menopause refers to permanent cessation of menstruation & 157 & $74.1 \%$ & 55 & $25.9 \%$ \\
\hline $\begin{array}{l}\text { During the menopause the ovaries produce an increasing amount of } \\
\text { hormones progesterone and oestrogen }\end{array}$ & 70 & $33 \%$ & 142 & $67 \%$ \\
\hline Menopause can begin before age 40 years & 129 & $60.8 \%$ & 83 & $39.2 \%$ \\
\hline Normally menopause begins with age between 40 - 55 years & 198 & $93.4 \%$ & 14 & $6.6 \%$ \\
\hline Menopause is a natural aging process & 147 & $69.3 \%$ & 65 & $30.7 \%$ \\
\hline Menopause is a disease & 174 & $82.1 \%$ & 38 & $17.9 \%$ \\
\hline After menopause is completed a woman can no longer become pregnant & 178 & $84 \%$ & 34 & $16 \%$ \\
\hline Early indicator of menopause is irregularities in menstruation & 177 & $83.5 \%$ & 35 & $16.5 \%$ \\
\hline $\begin{array}{l}\text { The use of hormone replacement therapy will decrease the symptoms of } \\
\text { menopause }\end{array}$ & 124 & $58.5 \%$ & 88 & $41.5 \%$ \\
\hline $\begin{array}{l}\text { Cardiovascular problems, osteoporosis are main risk factors of } \\
\text { menopause }\end{array}$ & 97 & $45.8 \%$ & 115 & $54.2 \%$ \\
\hline
\end{tabular}

Table 5: Frequency distribution of attitudes regarding menopause and its symptoms among study population.

\begin{tabular}{|c|c|c|c|c|c|c|}
\hline \multirow[t]{2}{*}{ Attitudes } & \multicolumn{2}{|c|}{ Disagree } & \multicolumn{2}{|c|}{ Neutral } & \multicolumn{2}{|c|}{ Agree } \\
\hline & No. & $\%$ & No. & $\%$ & No. & $\%$ \\
\hline A woman should see a doctor at the menopause & 47 & $22.2 \%$ & 62 & $29.2 \%$ & 103 & $48.6 \%$ \\
\hline Menopause is the best thing that ever happened to women & 47 & $22.2 \%$ & 79 & $37.3 \%$ & 86 & $40.6 \%$ \\
\hline $\begin{array}{l}\text { A good thing about menopause is that a woman can quit } \\
\text { worrying about getting pregnant }\end{array}$ & 27 & $12.8 \%$ & 79 & $37.3 \%$ & 106 & $50 \%$ \\
\hline Women are generally feeling better after menopause & 48 & $22.6 \%$ & 53 & $25 \%$ & 111 & $52.3 \%$ \\
\hline $\begin{array}{l}\text { After the change of life, a woman gets more interested in } \\
\text { community affairs than before }\end{array}$ & 123 & $58 \%$ & 55 & $25.9 \%$ & 34 & $16.1 \%$ \\
\hline $\begin{array}{l}\text { Unmarried women have a harder time than married women do } \\
\text { at the time of the menopause }\end{array}$ & 47 & $22.2 \%$ & 110 & $57.9 \%$ & 55 & $19.9 \%$ \\
\hline Menopause is an unpleasant experience & 54 & $25.4 \%$ & 86 & $40.6 \%$ & 72 & $33.9 \%$ \\
\hline Menopause is the loss of youth and beginning of the end of life & 68 & $32 \%$ & 67 & $31.6 \%$ & 77 & $36.3 \%$ \\
\hline $\begin{array}{l}\text { Natural approaches for treating menopausal symptoms are } \\
\text { better than hormone replacement therapy }\end{array}$ & 12 & $5.6 \%$ & 96 & 42 & 104 & $51.5 \%$ \\
\hline Menopause means no more worry about contraception & 25 & $11.8 \%$ & 82 & $38.7 \%$ & 105 & $49.5 \%$ \\
\hline
\end{tabular}


Table 6: Association between socio demographic characteristics and knowledge regarding menopause and menopausal symptoms.

\begin{tabular}{|c|c|c|c|c|c|}
\hline \multirow{2}{*}{ Characteristics } & \multicolumn{2}{|c|}{ Poor knowledge } & \multicolumn{2}{|c|}{ Good knowledge } & \multirow{2}{*}{ p value } \\
\hline & No. & $\%$ & No. & $\%$ & \\
\hline \multicolumn{6}{|l|}{ Age } \\
\hline$<50$ & 29 & $52.7 \%$ & 84 & $53.5 \%$ & \multirow{2}{*}{0.921} \\
\hline$>50$ & 26 & $47.3 \%$ & 73 & $46.5 \%$ & \\
\hline \multicolumn{6}{|l|}{ Marital status } \\
\hline Married & 50 & $90.9 \%$ & 125 & $79.6 \%$ & \multirow{3}{*}{0.043} \\
\hline Unmarried & 5 & $9.1 \%$ & 16 & $10.2 \%$ & \\
\hline Others & 0 & $0 \%$ & 16 & $10.2 \%$ & \\
\hline \multicolumn{6}{|l|}{ Education level } \\
\hline$<\mathrm{O} / 1$ & 33 & $60.0 \%$ & 50 & $31.8 \%$ & \multirow{2}{*}{0.000} \\
\hline$>\mathrm{O} / 1$ & 22 & $40.0 \%$ & 107 & $68.2 \%$ & \\
\hline \multicolumn{6}{|l|}{ Menopausal status } \\
\hline Pre menopause & 19 & $34.5 \%$ & 47 & $29.9 \%$ & \multirow{3}{*}{0.687} \\
\hline Menopausal transition & 11 & $20 \%$ & 28 & $17.8 \%$ & \\
\hline Post menopause & 25 & $45.5 \%$ & 82 & $52.2 \%$ & \\
\hline
\end{tabular}

The association between the socio demographic characteristics and knowledge regarding menopause and menopausal symptoms are depicted in Table 6 . The results indicated that those who were married had better knowledge regarding menopause when compared to their counterparts. This difference was statistically significant $(p<0.05)$. Those who had higher level of education had better knowledge regarding menopause and menopausal symptoms and this was statistically significant $(\mathrm{p}<0.05)$. Here were no association between age, menopausal status with the knowledge regarding menopause and menopausal symptoms (Table 6).

\section{DISCUSSION}

In the current study, mean age of menopause was found 47.84 years $(\mathrm{SD}=4.048)$ years which was similar to a study done in Sri Lanka, India and Pakistan. ${ }^{9,13-15}$ In this study more than half of the study population $107(50.5 \%)$ was postmenopausal and rest was 66 (31.1\%) premenopausal or $39(18.4 \%)$ in menopausal transition Waidyasekera et al, had similar findings in Sri Lanka. ${ }^{8}$

All the women in study sample had at least one menopausal symptom in their middle age. In this study, most commonly reported symptoms were hot flushes 157 (74.1\%), joint and muscular discomfort 138 (65.1\%), physical and mental exhaustion 136 (64.2\%), and sleep problems 126 (59.5\%). Among somatic symptoms hot flushes were most prevalent symptom in present study which is similar with the results of the studies reported in the past. ${ }^{9,13,16}$ Waidyasekera et al, reported that joint and muscular discomfort was the most prevalent menopausal symptom at that time and urogenital symptoms such as bladder problems 105 (49.5\%), vaginal dryness 95 $(43.9 \%)$ and sexual problems $70(33.1 \%)$ were reported least frequent symptoms. ${ }^{8}$ Urogenital symptoms were reported low in this study as well. Similar results were found from previous researches. ${ }^{13,16-17}$ In contrast, Chuni and Sreeramareddy's report showed the higher proportion of urogenital symptoms. ${ }^{12}$

Present study indicated that, symptoms most prevalent were among post-menopausal stage compared to pre and peri menopausal stages. All somatic and psychological symptoms were more prevalent in the postmenopausal stage and were significant $(p<0.05)$. These results were similar to the studies done by Sri Lanka in 2009 and 2019. ${ }^{8} 9$ However, in this study, there was no significant difference in urogenital symptoms. Some Western countries have reported higher occurrence of hot flushes, night sweats, decreased interest in sex and urogenital problems. ${ }^{18-20}$ Due to cultural issues, urogenital and sexual issues are not discussed openly in the Asian cultures and they think it is part of the ageing process.

This study reported that more than half $184(86.6 \%)$ of the women were not taking any medication for symptoms. Similar findings were reported by Nusrat et al. ${ }^{6}$

In the present study we found that $157(74.1 \%)$ of women were aware about the meaning of menopause and how it occurs. However, most $142(67 \%)$ of the women had poor knowledge regarding the hormonal changes during menopausal transition. Similar findings were reported by Nusrat et al. ${ }^{6}$ However, a study done by Wong and Liyana reported that $89 \%$ of women knew the definition of menopausal state and were aware of the hormonal changes. ${ }^{2}$ This could be due to that this study was done in an urban area, Malaysia. Majority 198 (93.4\%) of study population knew the age range of menopause and most 147 (69.3\%) women consider menopause as a natural aging process, only $38(17.9 \%)$ perceived it as a disease 
condition. Similar results were reported from Malaysia, Pakistan and India. ${ }^{2,6,15}$

Another important finding of the present study was most $124(58.5 \%)$ were aware about the hormone replacement therapy for menopausal symptoms. However, thisfindings were in contrast to findings in Malaysia and India. $^{2,21}$ This study findings showed that only 28 $(13.2 \%)$ were on medication and these findings were similar to previous studies. ${ }^{12,22}$

The most striking finding from the present study was clear underestimation of menopause related risk factors such as cardiovascular diseases and osteoporosis. Out of 212, only 97 (45.8\%) respondents had good knowledge about the main risk factors of menopause. This finding was similar to research in 2017. ${ }^{21}$ Wong and Liyana's report revealed that knowledge on associated health risks of menopause, participants knew that osteoporosis risk and heart disease risk in $76 \%$ and $36 \%$ respectively. ${ }^{2}$

Overall knowledge about menopause in our study revealed more than half of the respondents $157(74.1 \%)$ had good knowledge. This can be due to the fact that it was conducted in a semi urban area and the most of the women were educated above ordinary level. However, the results were in contrast to other studies reported in 2008 and $2017.6,14,21$

The main sources of knowledge related to menopause was by television $86.6 \%$, health care personnel $83 \%$ and $75 \%$ from books respectively. Research from 2007 also reported that $68.1 \%$ of women received information from health care personnel. ${ }^{2}$ These findings were in contrast to More's and Pathak's findings. ${ }^{15,21}$

Majority $103(48.6 \%)$ of the women in the study population had positive attitudes towards consulting a doctor after menopause and $86(40.6 \%)$ agreed they felt better after menopause. Most 104 (51.5\%) of them had positive attitude towards natural approaches for treating menopausal symptoms. These findings were similar to previous research findings from Asia. ${ }^{2,15,22}$ However, it was in contrast to Pathak's research results. ${ }^{21}$

Respondents in present study, majority of them had negative attitudes such as loss of youth and beginning of the end of life, menopause is an unpleasant experience like statements. This result was similar with the study done by Wong and Liyana and More in 2007 and 2018 respectively. ${ }^{2,15}$

The present study reported those who were married had better knowledge regarding menopause when compared to their counterparts. Those who had higher level of education had better knowledge regarding menopause and menopausal symptoms and this was statistically significant $(\mathrm{p}<0.05)$. Similar findings were reported by Pathak et al. ${ }^{21}$

\section{CONCLUSION}

Present study concludes that improving knowledge regarding the menopausal transition and its effects can change the attitudes among women in their middle life. Education, creating awareness and providing suitable interventions can be done to improve the quality of life of women through menopausal transitional period. Our study findings revealed that health care personnel especially public health midwives were the main source of knowledge. Therefore, public health midwives should promote and encourage women to actively participate in well women clinics which will help them to detect any menopausal transitional symptoms and give appropriate advice. Due to cultural issues urogenital symptoms were not disclosed openly. Health care personnel need to update their knowledge continuously so that they can impart proper knowledge regarding menopausal transition to women in their community thereby improving their quality of life.

\section{ACKNOWLEDGMENTS}

Authors would like to express our gratitude and thanks to the Medical Officer of Health Malimbada, Public Health Midwives and the participants who gave their consent and for their active participation in the research.

\section{Funding: No funding sources}

Conflict of interest: None declared

Ethical approval: Ethics Review Committee, Faculty of Medical Sciences, University of Sri Jayewardenepura, Sri Lanka

\section{REFERENCES}

1. Shakila P, Sridharan P, Thiyagarajan S. Knowledge and symptoms of menopause among Srilankan women academicians. Int $\mathrm{J}$ Multi Res Develop. 2015;2(1):336-42.

2. Wong LP, Ah NL. A survey of knowledge and perceptions of menopause among young to middleaged women in federal territory, Kuala Lumpur, Malaysia. J Univ Malaya Med Centre. 2007;10(2):22-30.

3. Li RX, Ma M, Xiao XR, Xu Y, Chen XY, Li B. Perimenopausal syndrome and mood disorders in perimenopause: prevalence, severity, relationships, and risk factors. Med. 2016;95:32(e4466).

4. Taherpour M, Sefidi F, Afsharinia S, Hamissi JH. Menopause knowledge and attitude among Iranian women. J Med Life. 2015;8(Spec Iss 2):72-6.

5. Kagawa-Singer M, Wu K, Kawanishi Y, Greendale GA, Kim, S, Adler SR, et al. Comparison of the menopause and midlife transition between Japanese American and European American women. Med Anthropol Quarterly. 2002;16(1):64-91.

6. Nusrat N, Nishat Z, Gulfareen H, Aftab M, Asia N. Knowledge, attitude and experience of menopause. $\mathrm{J}$ 
Ayub Med Coll Abbottabad. 2008;20(1):56-9. PMID: 19024187.

7. Chen RJ, Chang TC, Chow SN. Perceptions of and attitudes toward estrogen therapy among surgically menopausal women in Taiwan. Menopause. 2008;15(3):517-23.

8. Waidyasekera H, Wijewardena $\mathrm{K}$, Lindmark G, Naessen T. Menopausal symptoms and quality of life during the menopausal transition in Sri Lankan women. Menopause. 2009;16(1):164-70.

9. Rathnayake N, Lenora J, Alwis G, Lekamwasam S. Prevalence and severity of menopausal symptoms and the quality of life in middle-aged women: a study from Sri Lanka. Hindawi, Nurs Res Pract. 2019; Article ID 2081507.

10. Rahman SASA, Zainudin SR, Mun VLK. Assessment of menopausal symptoms using modified menopause rating scale (MRS) among middle age women in Kuching, Sarawak, Malaysia. Asia Pacific Family Med. 2010;9(1):5.

11. Annual Health Bulletin of Sri Lanka, 2018. Available at: www.health.gov.lk. Accessed on $20^{\text {th }}$ March 2020.

12. Chuni N, Sreeramareddy CT. Frequency of symptoms, determinants of severe symptoms, validity of and cut-off score for Menopause Rating Scale (MRS) as a screening tool: a cross-sectional survey among midlife Nepalese women. BMC Women's Health. 2011;11:30.

13. Mazhar SB, Rasheed S. Menopause rating scale (MRS), a simple tool for assessment of climacteric symptoms in Pakistani women. Ann Pak Inst Med Sci. 2009;5(3):58-161.

14. Malik HS. Knowledge and attitude towards menopause and hormone replacement therapy (HRT) among postmenopausal women. Therapy. J Pak Med Assoc. 2008;11:12.

15. More S, Sujatha P, Karthiga. Knowledge, attitude and experiences of menopause in the postmenopausal women at a tertiary care center: a cross sectional study. Int J Reprod Contracept Obstet Gynecol. 2018;7:4758-61.

16. Sharma AS, Khan Z. Prevalence of climacteric symptoms in menopausal and perimenopausal women. Int J Reprod Contracept Obstet Gynecol. 2019;8:406-11.

17. Khatoon F, Sinha P, Shahid S, Gupta U. Assessment of menopausal symptoms using modified menopause rating scale (MRS) in women of Northern India. Int J Reprod Contracept Obstet Gynecol. 2018;7:947-51.

18. Greenblum CA, Rowe MA, Neff DF, Greenblum JS. Midlife women: symptoms associated with menopausal transition and early postmenopause and quality of life. Menopause. 2013;20(1):22-7.

19. Greendale GA, Gold EB. Lifestyle factors: are they related to vasomotor symptoms and do they modify the effectiveness or side effects of hormone therapy?. Am J Med. 2005;118(2):148-54.

20. Jokinen K, Rautava P, Makinen J, Ojanlatva A, Sundell J, Helenius H. Experience of climacteric symptoms among 42-46 and 52-56-year-old women. Maturitas. 2003;46(3):199-205.

21. Pathak V, Ahirwar N, Ghate S. Study to assess knowledge, attitude and practice regarding menopause among menopausal women attending outdoor in tertiary care centre. Int $\mathrm{J}$ Reprod Contracept Obstet Gynecol. 2017;6:1848-53.

22. Leena AJ, Varghese AP. Prevalence of menopausal symptoms and perceptions about menopause among postmenopausal women attending gynaecology OPD at GMC Idukki, India. Int J Reprod Contracept Obstet Gynecol. 2017;6:413-6.

Cite this article as: Perera ST, Goonewardena SE. Prevalence, knowledge and attitudes of menopausal symptoms among women aged 40-60 years and their associated factors in a semi urban area, Matara district, Sri Lanka. Int J Reprod Contracept Obstet Gynecol 2020;9:2771-7. 